\title{
Os Elementos Éticos da Formação do Juiz Refle- tidos Nas suas Decisões
}

\author{
MARIA DE FÁTIMA AGUIAR GOULART \\ RIBEIRO NUNES MAIA \\ Aluna da FA7, orientada pelo prof. Élder Lacerda. \\ goulart.fatima@gmail.com
}

Sumário: Introdução; 1) Sobre os conceitos de direito, justiça, ética e valor; 2) A visão de justiça segundo Aristóteles, Sto. Tomás de Aquino, Immnuel Kant e J. Rawls; 3) O surgimento de um novo direito; 4) $\mathrm{O}$ acervo das experiências do julgador; 5) A herança cultural; 6) As matrizes familiares; 7) O ambiente escolar; 8) As leituras e os professores; Considerações finais; Referências bibliográficas.

Resumo: Trata-se de um trabalho através do qual pretende a aluna demonstrar a importância de uma boa formação ética dos juízes, tendo isso um objetivo maior, qual seja a aplicação da lei, dentro de um conceito de Justiça. Para tanto, recorre a autora à Filosofia, principalmente às lições de Aristóteles, Sto. Tomás de Aquino, Kant e J. Rawls, a fim de poder enumerar as qualidades que melhor irão definir o caráter de um bom juiz, quais sejam a sensibilidade, o desprendimento mas, e sobretudo, o amor à Justiça. Lembrando sempre tratar-se o aplicador do direito de um ser humano, dotado de grande poder, e tendo em vista deter ele a faculdade de decidir sobre os bens mais valiosos de seus semelhantes, quais sejam a liberdade e a vida, atenção especial foi dada ao fato de que os juízes, em tomando consciência desse poder, não o ultrapassem, ao contrário, revistam-se da humildade necessária para, se possível, se colocarem no lado mais carente, mais fraco. Dessa maneira, seguramente, poderão elaborar sentenças mais justas, contribuindo, desta feita, para a harmonia da sociedade para a qual foram destinados a servir.

Palavras-chave: Ética. Direito. Juiz. Decisões. 


\section{CO INTRODUÇÃo}

Ao elaborarmos este trabalho tivemos como objetivo procurar demonstrar a importância da formação ética dos indivíduos e, conseqüentemente, a dos profissionais do direito, especialmente os juízes, por entendermos ser a ética um dos pilares mais importantes sobre os quais se constroem seres humanos excelentes.

Os métodos científicos utilizados foram o da revisão, que parte do conceito geral de ética para o conceito mais específico desta na aplicação de Direito; outro método foi o dialético, ao efetuarmos um debate entre os vários conceitos abordados.

Mencionamos como palavras-chaves deste trabalho: ética, direito, justiça, juízes e sentenças.

E, para nos situarmos hoje, em relação à ética, mister se faz nos debruçarmos sobre a história do Brasil, em especial a do Brasil República, quando verificamos a ocorrência de inúmeras crises institucionais, principalmente aquelas inerentes aos períodos em que vigoraram os chamados regimes ditatoriais, a ditadura de Getúlio e a ditadura militar de 1964, apesar de certas opiniões em sentido contrário; com efeito, há pontos positivos que podem ser assinalados, quiçá confirmando a regra de que nas obras humanas sempre se pode encontrar algo de valioso.

Ao terminar a ditadura militar de 1964, eis que o Brasil se encaminha na consecução de uma democracia sólida, a qual alcançou, embasada em instituições fortes, mas, lamentavelmente, com alguns mandatários que nem sempre estiveram à altura dos novos valores da nacionalidade, havendo momentos em que os responsáveis por estas instituições não demonstraram por elas o zelo e a competência que deveriam.

E isso se faz sentir, inúmeras vezes, em ocasiões em que a ética deveria ocupar posição de destaque na solução dos problemas postos, o que vem levando o povo brasileiro não só à desolação e à tristeza, mas até à desesperança.

E a propósito do que acabamos de afirmar, citamos o notável poeta Luís de Camões, na sua obra Os Lusíadas, Canto III, estrofe 138:

Que, vindo o Castelhano devastando

As terras sem defesa, esteve perto

De destruir-se o Reino totalmente,

Que um fraco Rei faz fraca a forte gente.

Verificamos, portanto, que não é uma crise de democracia que precisamos debelar, mas uma outra, tão grave quanto esta: a da moralidade.

E é com esse objetivo que se faz imprescindível um Poder Judiciário eficiente e imparcial, que permita a preservação das instituições democráticas, conseguidas com grandes sacrifícios, e ajude a minimizar a crise moral que sobre nós paira, acabando com a impunidade, ou melhor, aplicando as penalidades a quem as merece. 
Tendo como norte o que afirmamos, nos motivamos a dissertar sobre o tema “Os Elementos Éticos da Formação do Juiz Refletidos nas suas Decisões”, pela convicção que temos de serem eles, além de outros, obviamente, os que nos poderão auxiliar a diminuir este problema que, no momento, aflige sobremaneira nossa sociedade.

Os romanos tinham uma frase terrível para estigmatizar o juiz que não fazia da sua função a atividade de realizar a Justiça; para eles, "judez damnatur, ubi nocens absolvitur” (o juiz é condenado onde o culpado é absolvido).

\section{c Sobre os Conceitos de Direito, de JustiçA, DE ETICA E DE VALOR}

Antes de iniciarmos, propriamente, o tema em sua essência, gostaríamos, face ao enfoque ético que pretendemos lhe dar, relacionar alguns conceitos, como: o Direito, a Justiça, a Ética e o Valor.

\subsection{DiREITO}

Em sentido geral e fundamental, o Direito é a técnica da coexistência humana, ou seja, a técnica voltada a tornar possível a coexistência entre os homens.

Nesse sentido, somente as sociedades humanas produzem a noção de Direito, ou seja, nas sociedades pré-humanas (as horas dos trogloditas) não se conhecia a idéia de Direito; como técnica, o Direito se concretiza em um conjunto de regras e têm essas regras como objeto o comportamento dos homens entre si e as suas múltiplas e variadas relações.

Quanto à validade do Direito, dispomos, na história do pensamento filosófico e jurídico, de quatro concepções:

(A) a que considera o Direito Positivo como fundado em um Direito Natural eterno, imutável e necessário;

(B) a que julga o Direito fundado na moral e o considera uma forma diminuída da moralidade;

(C) a que reduz o Direito à força, isto é, uma realidade histórica, politicamente organizada; e

(D) a que tem o Direito como técnica social.

\subsection{JuSTIÇA}

A justiça representa a ordem das relações humanas ou a conduta de quem se adapta a esta ordem.

O conceito de Justiça pode distinguir dois principais significados: (a) aquele pelo qual a Justiça é a conformidade da conduta a uma norma; e (b) aquele pelo qual a justiça constitui a eficiência de uma norma, entendendo-se por eficiência de uma norma a medida de sua capacidade de tornar possíveis as relações entre os homens. 
O conceito empregado por primeiro relaciona-se a julgar o comportamento humano ou a pessoa humana (e esta última com base em seu comportamento); o segundo significado é empregado para julgar as normas que regulam o próprio comportamento.

No primeiro significado, a justiça é a conformidade de um comportamento a uma norma, e, no âmbito deste significado, a polêmica filosófica, jurídica e política verte somente sobre a natureza da norma que é tomada em exame. Esta pode ser a norma da natureza, a norma divina ou a norma positiva.

O famoso filósofo grego Aristóteles tem estas palavras sobre a justiça:

Sendo que o transgressor da lei é injusto, enquanto que quem se conforma à lei é justo, é evidente que tudo aquilo que é conforme a lei é de qualquer forma justo; de fato as coisas estabelecidas pelo poder legislativo são conforme a lei e dizemos que cada uma delas é justa (Abbagnano, Nicola. Dicionário da Filosofia, p. 565).

De acordo com Aristóteles, portanto, a Justiça constitui-se uma virtude perfeita e inteira; inteira, por compreender todas as outras virtudes, e perfeita porque quem se utiliza da Justiça se utiliza não somente em relação a si mesmo, mas, e principalmente, em relação aos outros.

\section{3. ÉTICA}

Poder-se-ia dizer que Ética é a ciência da conduta e que há duas concepções sobre esta ciência:

1 - a que a considera como a ciência do fim, a que a conduta dos homens se deve dirigir e dos meios de que se utiliza para atingir tais fins, e

2 - a que a define como sendo a ciência do móvel da conduta humana e que procura determinar tal móvel visando disciplinar essa mesma conduta.

Nessas duas concepções, a primeira delas nos diz do ideal a que o homem se dirige pela sua própria natureza, ou seja, da "natureza”, da "essência”, ou da substância do homem; a segunda nos ensina sobre os motivos da conduta humana.

Podem as referidas concepções eventualmente se confundir, pois é certo que ambas se constituem em uma definição do bem.

Entretanto, esta noção de bem, se mostra ambígua, porque o bem pode significar o que é (pelo fato de que é) ou o que é objeto de desejo. E estes significados, sim, aproximam-se das concepções já mencionadas.

\subsection{VALOR}

Desde que o mundo é mundo, valor indica a utilidade e o preço dos bens materiais, e a dignidade ou o mérito das pessoas.

Na filosofia, no entanto, este significado é de menor importância; valor, de acordo com o seu significado filosófico, indica qualquer objeto de preferência ou 
de escolha, tendo este significado surgido com os filósofos estóicos que introduziram o termo "valor" no domínio da ética e chamaram os objetos de escolhas morais.

Assim se deu porque entendiam eles o bem em sentido subjetivo, e puderam considerar os bens e as suas relações hierárquicas como objetos de preferência ou de escolha.

\section{A Visão de Justiça Segundo Aristóteles, Sto. Tomás de Aquino, ImManuel Kant E J. RAWLS}

A justiça, os direitos e as liberdades de base garantem a todos as condições do desenvolvimento e do exercício de duas faculdades morais: o senso de justiça e a concepção do bem. (Frase de autoria de J. Rawls, citada em Ética e Justiça, 2003, p. 70).

Quando lemos Aristóteles, Santo Tomás de Aquino, Immanuel Kant e J.Rawls, apercebemo-nos da importância que detêm aqueles cuja função é aplicar a Lei e, conseqüentemente, decidem sobre a vida e a liberdade das pessoas.

\subsection{Aristóteles}

Dentro de sua teoria finalista, ensina-nos que a Justiça é a alma da ética e da política e que não é ela somente um feixe de normas legais cegas, de aplicação inflexível. A justiça, a verdadeira justiça, sempre se adequa às necessidades e à história da humanidade. Ensina-nos Aristóteles, também, que a justiça para ser justa tem que estar submetida ao juízo prudencial do "sábio”, ou seja, do juiz.

É de nosso conhecimento que para qualificarmos um cidadão de "bom" ou "mau" não podemos avaliá-lo tão-somente pelo modo como cumpre a lei. Ele será bom ou mau, se detiver, ou não, em seu espírito, uma vontade permanentemente cultivada para cumprir seus deveres legais junto à sociedade de que faz parte. Ou seja, de acordo com o ponto de vista aristotélico, o cidadão bom acumula em sua alma muitas virtudes, mas é ao deter, principalmente, em sua alma a virtude da Justiça, que vale mais do que a lei, que ele poderá ser classificado de "bom”, porque a lei de nada vale se não for praticada por pessoas virtuosas.

É, pois, a virtude que ameniza o rigor muitas vezes exagerado da lei e é, também, a virtude que vai indicar o que seja justo em cada um dos inúmeros casos concretos sobre os quais o juiz tem que se deparar. 
Vejamos, então, os ensinamentos tomistas, no que se referem à justiça.

\subsection{Sto. Tomás de Aquino}

Para esse filósofo e teólogo do Cristianismo, a justiça é uma ponte que põe em contato a comunidade da fé com a sociedade política e que constitui o ponto nevrálgico da ética.

Uma das características que Sto. Tomás nos mostra, e que deveria caracterizar os que "governam" a Justiça, seria a humildade, tendo em vista a variedade da natureza e a fragilidade da condição humana. E, dentro desta concepção, citamos André Comte Sponville, que nos ensina que "a humildade é a virtude do homem que sabe não ser Deus.”

Afirma Sto. Tomás que a ordem jurídica e o Estado devem ater-se intensamente à ética, para que lhes seja possível a efetivação de um julgamento moral do Direito.

Num trabalho cujo objeto maior é a justiça e as suas relações com o Direito, o caráter daqueles que aplicam tanto um como o outro, ou seja, o caráter dos juízes, seria quase impossível não abordarmos o pensamento de Immanuel Kant a propósito desse assunto.

\subsection{KanT}

Para Kant, “o Direito é o conjunto das condições sob as quais o arbítrio de um pode unir-se ao arbítrio de outro, seguindo uma lei universal de liberdade".

Para ele, igualmente, "justa é toda a ação que permite a liberdade do arbítrio de cada um coexistir com a liberdade do outro, segundo uma lei universal”.

Essencial à harmonia da sociedade é a ética das normas que se constitui, segundo Immanuel Kant, em uma doutrina moral de elevadíssimo valor.

E, agora, para concluir o relato dos entendimentos que buscamos para utilizar neste trabalho, e que nos vão servir de base para o tema principal, faremos um breve comentário sobre J. Rawls.

\subsection{J. RAWLS}

Esse autor afirma ser a justiça não uma virtude, nem um direito, mas, antes de tudo, um princípio fundador de uma sociedade bem ordenada. Segundo ele, a importância da justiça não está nem nas instituições nem nas práticas sociais, mas está, isto sim, concentrada na distribuição das vantagens e dos ônus sociais.

\section{$\boldsymbol{V}$ O Surgimento de um Novo Direito}

É fácil a constatação, hoje em dia, do surgimento de uma nova Ciência do Direito. Enquanto que num passado não muito remoto a preocupação jurisdicional se prendia exclusivamente à letra da lei, hoje verificamos que o Profissional da Lei, o Juiz, detém-se muito mais numa interpretação legal relativa à razoabilidade dessa lei, à justiça encerrada nessa lei. Enfim, detém-se, sobremaneira, no aspecto sócio-jurídico 
das normas de que irá se utilizar para formular seus conceitos e elaborar suas decisões.

E observamos que, hodiernamente, a expressão tão usada "ao arrepio da lei” significa muito mais a ausência de sensibilidade do Juiz que, ao interpretar essa lei, deixou de observar o alcance social que há em sua essência, do que a anteriormente utilizada interpretação literal dessa lei.

Face à evolução do Direito, solicitando de seus profissionais além dos conhecimentos acadêmicos, teóricos, muito mais sensibilidade voltada para as necessidades de justiça das pessoas, procuramos tentar explicar e sugerir alguns procedimentos mediante os quais poderá ser possível a melhor adequação às necessidades de Justiça, no trabalho desses importantes aplicadores da Lei.

Pertinente citar novamente J. Rawls:

A Justiça, numa democracia de proprietários (ou de um regime socialista liberal), consiste em realizar uma sociedade como sistema eqüitativo de cooperação entre cidadãos livres e iguais (Ética e Justiça, 2003, p. 68).

Vivemos num mundo em que os bens são limitados e ilimitada é a ganância de cada indivíduo por esses bens. Daí a necessidade premente de um princípio que organize a distribuição desses valores dentro da comunidade. Pode-se dizer que a matriz dos conflitos (individuais e grupais, dentro da sociedade) é representada sobretudo pela escassez (ou limitação) dos bens em face da crescente demanda pela sua posse e uso, ao mesmo tempo, por uma pluralidade de indivíduos.

Por outro lado, são necessárias regras certas que propiciem uma ordem jurídica estável, pois só assim é possível acreditar que as relações sociais serão caracterizadas pela segurança.

Os Tribunais e as Cortes de Justiça só poderão ser respeitados quando os juízes que as constituem se utilizarem de suas ferramentas de trabalho, principalmente da lei e do Direito, para servirem e implementarem a Justiça.

E aprendemos das lições de Kant que essa Justiça a ser servida e implementada por esses juízes deverá ser, essencialmente, fundamentada no respeito e na autonomia de cada pessoa.

Esta evolução se faz necessária, mais ainda, na sociedade em que vivemos, formada por tantas gentes, de tantas feições diferentes, de carências imensuráveis, onde a inflexibilidade da lei, na maior parte das vezes, lhes será muito mais injusta do que a interpretação daquele juiz que, como verdadeiro servidor da lei, fará sempre reinar a justiça; vê-se, aqui, que há um conflito potencial entre as dicções da Lei e a sua interpretação socialmente valorada.

A evolução desejada, no nosso caso particular, seria, portanto, voltada para amenizar, dentro de um plano sócio-jurídico, as injustiças que, quase sempre em nome da instauração da moralidade e da lei, são dirigidas a esses que não têm 
ninguém para defendê-los, a não ser aqueles que constituem o poder público, na maioria dos casos o Poder Judiciário.

\section{O ACERVo das EXPERIÊNCIAS do JUlgador}

Ao analisarmos detalhadamente as sentenças judiciais, quando efetivamos um estudo mais cuidadoso dessas sentenças, percebemos, e até podemos concluir, sobre as diretrizes de que o julgador lançou mão para elaborar o seu raciocínio.

Não existe dúvida de que é o Direito Positivo que vai influenciar a tarefa da produção ou da elaboração da sentença judicial, logicamente limitada ao quadro normativo disponível. Mas podemos afirmar, sem temer incidir em erro que, consciente ou inconscientemente, posturas prévias aconteceram às quais o juiz se filiou, sendo-lhes mais ou menos fiel.

A maior ou menor fidelidade do juiz a esses dados da ordem (ou do ordenamento jurídico) seguramente se radica no acervo de suas experiências anteriores, acumuladas no correr de sua vida, compondo-se das suas várias vivências prévias, dos dados de sua cultura formal (escolar) ou da cultura do lugar (ou classe social) de onde é ele originário.

É claro que são muitas as posições intelectuais possíveis a serem adotadas diante de um conflito concreto. Mas importa relatar, de saída, que essas posições assumem, no mínimo, duas formas conhecidas, máxime quando em um dos pólos da relação controvertida se acha o Poder Público:

(a) a postura de "defesa do interesse público" e

(b) a postura de "defesa do interesse individual".

Revela essa dualidade de posturas, ou uma ou outra postura, qual seja a de que esses dois grupos de interesses estariam em contradição ou seriam de árdua conciliação - e isso já é uma parte da decisão que o juiz vai adotar.

Pode ser dito, portanto, que pareceria intuitiva e até mesmo inevitável a aplicação das idéias do juiz na realização dos julgamentos judiciais, tendo-se em conta que cada apreciação das razões deduzidas pelos litigantes envolverá sempre uma indispensável atitude crítica por parte do julgador, tanto para rejeitá-las, quanto para acolhê-las.

Essa crítica, que é própria e inexcluível de qualquer ato humano de julgar, é calcada diretamente nas convicções pessoais de quem o empreende, nutre-se de todas as suas experiências anteriores e dos conhecimentos que foi incorporando ao longo de sua existência, não apenas os conhecimento teóricos, intelectuais ou acadêmicos, sem dúvida alguma enormemente relevantes, mas também os que lhe advieram de outras fontes, como as dos duros embates da vida e das suas adversidades, estas de inestimável valor. 
Como se pode observar, até sem muita dificuldade, o saber humano passa, na evolução do processo aquisitivo do conhecimento, da fase da "admiração ingênua das coisas do mundo" (algo assim como a visão das crianças) ao "comportamento dogmático" (que aceita um mundo como dado ou completo) e, em seguida, "à atitude crítica” (a perspectiva do mundo a construir-se).

É claro que a percepção das coisas do mundo e a sua compreensão sofre evoluções e retrocessos, avanços e recuos, mas será possível afirmar que os conteúdos de uma decisão judicial sempre refletiriam essa percepção e essa compreensão, ou seja, a sua capacidade para ver, num universo vasto (ou até infinito) de relações possíveis, uma que servirá para fornecer a resolução de um conflito.

A escolha dessa solução é que tem por matriz o conjunto das experiências do julgador, representando o seu espírito pela imensidão de valores éticos que absorveu desde o seu nascimento, os planos familiares para si e para os outros membros da família, as frustrações pessoais e os dramas dos seus parentes, as vitórias advindas da sorte ou do esforço — enfim, no seu julgamento o Juiz deixa vir tudo isso à tona e nisso mergulha para formatar a sua resolução.

\section{A Herança Cultural}

A relevância da herança cultural na formação da decisão judicial já foi assinalada por muitos autores jurídicos, como se vê nesta passagem de Napoleão Nunes Maia Filho:

Quando o Juiz, pelas suas multivivências, possui amplos conhecimentos culturais, será sempre preferível que os aplique na solução das causas, sem o que sua sentença será apenas um ato de lógica formal, de subsunção da hipótese à norma, sem a inclusão dos elementos vívidos e autênticos, que se colhem no dinamismo da vida social. Não se há de confundir, nesse terreno, a ciência ou o conhecimento acadêmico, de importância que não precisa ser assinalada, da qual o juiz poderá ser sofisticado detentor, com a cosmovisão que lhe dá a percepção das coisas, fazendo-o contemporâneo das suas próprias idéias (As Regras da Experiência Comum na Formação da Convicção do Julgador, 2000, p. 57).

Assinala o Ministro Moacir Amaral Santos que quanto maior for o cabedal de conhecimento do Juiz tanto mais autêntica será a formação do seu juízo, dizendo:

As regras da experiência comum, que surgem da observação do que comumente acontece, e fazem parte da cultura normal do Juiz, 
serão por este livremente aplicadas, independentemente de prova das mesmas. O Juiz não pode desprezá-las quando aprecia o conteúdo de um testemunho, ou mesmo de um documento, para extrair a verdade dos fatos testemunhados ou documentados (Comentários ao CPC, 1976, p. 53).

\section{$\boldsymbol{x}$ As Matrizes Familiares}

A primeira matriz mental da pessoa humana é, sem dúvida alguma, a sua família, qualquer que seja a sua estrutura orgânica: seja uma família organizada ou não, ou seja mesmo uma situação de "ausência de família".

É fácil compreendermos que aqueles que nascem numa família cujo comportamento se pauta em valores efetivamente valiosos tenham melhores condições, desde o berço, de incorporar a suas personalidades qualidades como decência, honestidade, respeito ao próximo e, opostamente, os que forem fruto de uma ausência de família onde a orientação ética não prevaleça terão dificuldades para assimilar esses valores, que lhes serão de muita utilidade durante toda a vida, determinando o seu comportamento e o lugar bom ou mau que virão a ocupar no meio da sociedade.

\section{O AMbiente Escolar}

Imaginando-se que a criança possa freqüentar uma escola, ter colegas e professores, ter convívio com outras crianças da sua idade e desenvolver as suas aptidões pessoais, antecipa-se o universo de relações que a sua mente começa a formar.

O juiz, como todo e qualquer ser humano, carrega na sua alma, ora como lembranças gratas, ora como cicatrizes, todas essas vivências pessoais, mesmo as dos anos mais verdes da infância; aquilo que percebeu com seus olhos infantis e as interpretações que fez de tudo o que captou, tudo isso vai se refletir na sua atividade judicante, às vezes como atitude de resgate do que lhe foi tirado pelas asperezas da vida pessoal (atitude compassiva), às vezes como atitude de revanche (atitude indiferente).

\section{As Leituras e os Professores}

As leituras e os professores que a pessoa teve ao longo da experiência escolar são outra fonte importante para se compreender a atitude dos juízes. Quem teve, no curso jurídico, professores com pendores para a Filosofia do Direito, por exemplo, terá o espírito orientado para outros valores, quando comparada a sua 
conduta judicante com a de outro juiz que teve professores mais voltados para a visão do Direito como uma Ciência.

Seguramente que aqueles que cultivam o salutar hábito da leitura desde meninos vão dispor de uma casta de informações, certamente valiosíssima, no momento da elaboração de uma sentença. Além do mais, é sempre bom lembrar que são os valores morais e não a lei, propriamente dita, que irão conceder os elementos mais adequados quando se tem como tarefa decidir sobre o destino de seres humanos.

E esses valores morais indispensáveis serão, também, transmitidos pelos professores, em todos os graus da hierarquia do aprendizado, desde o jardim de infância até aos cursos de pós-graduação, influenciando de maneira extremamente significativa aqueles que os apreenderam.

\section{Considerações FinaIS}

Antes, os sistemas legais fundamentavam-se na crença de que o juiz deveria concentrar sua atuação na letra da lei, fria e impessoal e, por conseguinte decidir em cima dela, sem levar em consideração o elemento humano, elaborando suas decisões como se estivesse resolvendo problemas inerentes às ciências exatas.

Face à evolução que vem-se sentindo, as reflexões que os juízes deveriam fazer sobre si mesmos, com o objetivo de melhor se conhecerem e de, conseqüentemente, poderem se corrigir e se elevar como seres humanos, não se sentiam necessárias.

Hoje, felizmente, está aquele método ultrapassado, devendo pois sempre ser facilitadas aos juízes condições de autoconhecimento e de aprimoramento pessoal, porquanto esses elementos irão propiciar uma interpretação mais próxima das reações que os caracterizem e oferecer-lhes materiais de modo a possibilitarlhes resultados mais equilibrados e racionais em suas notáveis funções.

Conveniente se faz a compreensão da função social das decisões judiciais e de como essas decisões poderão, se não forem abalizadas dentro de princípios éticos e elaboradas por profissionais dotados de caráter, sensibilidade, desprendimento e, sobretudo, amor à Justiça, acarretar enormes prejuízos à segurança jurídica.

Longe o tempo de Montesquieu em que o juiz deveria ser, simplesmente, "la bouche que prononce les paroles de la loi” (a boca que profere as palavras da lei).

Presentemente, não devem os juízes apenas dizer o direito; muito mais do que isso, têm eles que fazer Justiça, obviamente, sempre ao amparo da lei.

E é por isso que esta função de extrema nobreza não pode ser concedida a seres humanos medíocres, mesquinhos, nem pretensiosos, sempre a quererem abusar do poder que detêm. Some-se a isso, também, a necessidade de serem os 
juízes seres participativos da sociedade a que servem, para que lhes seja possível atendê-la da melhor maneira.

Finalmente, concluo transcrevendo a notável lição de Vallet Goytisolo:

Nossa arte faz parte daquela da Justiça; porém, para desenvolvêla, não basta só o conhecimento das leis. Faz falta, ainda, o sentimento do justo. Este é um pressuposto para poder compreender a Justiça, como o sentido da proporção, da beleza, da cor, o som para chegar a expressar o belo. Mas, de igual modo que todos os sentidos corporais — vista, audição, gosto, tato e olfato — podem educar-se, também o sentimento do justo pode ser educado e guiado através do arsenal de dados subministrados pela experiência jurídica (Recrutamento e Preparo de Juízes, 1992, p. 128).

\section{cơ RefERÊNCIAS BibliográficAs}

ARISTÓTELES. Ética a Nicômaco. São Paulo: Martin Claret, 2005.

CAMÕES, Luís de. Os lusíadas. 3. ed. Porto: Porto, 1974.

COMTE-SPONVILLE, André. Pequeno tratado das grandes virtudes. São Paulo: Martins Fontes, 2004.

MAIA FILHO, Napoleão Nunes. Quatro estudos temáticos de processo civil. Fortaleza: UFC, 2004.

NALINI, José Renato. Recrutamento e preparo de juízes. São Paulo: RT, 1992.

PEGORARO, Olinto A. Ética é justiça. 8. ed. Petrópolis: Vozes, 2003.

\section{ETHICAL ASPECTS ON THE JUDGE'S BACKGROUND AND HIS SENTENCES}

Aвstract: This article demonstrates the importance of a judge's good educational and ethical background, in order to obtain fair trials. Philosophical concepts by Aristotle, St. Thomas Aquinas, Kant and J. Rawls are here exposed. As any other human being, the judge has to deal with his personal dilemmas and, at the same time, with other people's demands.

KeYwords: Ethics. Law. Judge. 